\title{
Herding in Virtual Teams: A Three Stage Model
}

\author{
Anil Aggarwal \\ University of Baltimore \\ aaggarwal@ubalt.edu
}

\begin{abstract}
Herding can lead to functional or dysfunctional teams resulting in optimal, sub-optimal or no outcome. We study herding in context of teams with a measurable outcome and discuss how they impact group performance. Our study indicates that herding is dynamic and develops as levels of communication changes with incompetence and indifference of members. some group member(s) herd while others continue This study is significant since it includes indifference and incompetence as two new factors that can lead to herding possibly leading to sub optimal results. Professors/managers making teams should pay attention to incompetence to avoid herding and suboptimal results. Future research areas are also discussed.
\end{abstract}

\section{Introduction}

Herding in groups can be counterproductive as it leads to what Conradt et al (2003) has called "Despotism" (following a dominant person or groups), especially when the dominant person or groups themselves are not competent. This can lead to sub optimal decisions or loss of creative ideas. Some groups herd while others do not.

Questions arises, Does herding impact outcome? To study this we analyze four factors: indifference, incompetence, imitation and incompetence, here, is defined when group member(s) is(are) not familiar or does not have domain knowledge to work on the task. Indifference is defined when group member(s) is(are) not concerned about the outcome of the task. Imitation is defined when member(s) agree with the dominant member(s) or group(s). Interaction is defined when members engage in task and are equal contributor.

This paper addresses these questions and discusses future research directions.

\section{Literature Review}

Herding in groups, however, may occur due to group member's characteristics and composition (Aggarwal,
2014, Siu, 2016; Harrisburg et al, 2007), leadership (Reynold, 2015; Chi et al, 2012; King et al,2009 ), information sharing (Conradt et al, 2003). Broeder et al (2016) described three levels of herding, weak, semi strong and strong herding behavior as related to pension funds. They argue "Weak herding occurs if pension funds have similar rebalancing strategies. Semi strong herding arises when pension funds react similarly to other external shocks, such as changes in regulation and exceptional monetary policy operations. Finally, strong herding means that pension funds intentionally replicate changes in the strategic asset allocation of other pension funds. Without an economic

reason".

Shen et al (2016) argue the quality and credibility affects adoption of online reviews and this behavior is influenced by two key determinant of herding behavior, namely background homophily and attitude homophily.

Several researchers (Aggarwal, 2016; Harrison et al 2010; Harrison et al 2007; Haughton et al, 2008; King et al, 2009; Knippenberg et al, 2004; Kippenburg et al, 2007; Kravitz, 2005 ) have identified factors that affect group behavior. These include group size, group composition and both functional and surface diversity. Commenting on group behavior, Dyer et al (2009) found that both group size and the presence of uninformed individuals can affect the speed with which small human groups (eight people) decide between two opposing directional preferences and the likelihood of the group splitting possibly creating dysfunctional groups. Several researchers (Aggarwal, 2014; Harrison et al, 2010; Kravitz, 2005 etc.) have studied why groups become dysfunctional and/or produce sub optimal results. Aggarwal (2016) noted lack of functional expertise among group member(s) or a "bad" apple can result in dysfunctional groups. However dysfunctional group are not studied in this paper.

Very little research related to herding in small virtual group has been studied. Given limited research in this area, this paper studies herding for small groups 
in controlled setting. Next section describes the model followed by experiment and the conclusion.

\section{The Model}

The study proposes a three stage dynamic model to study herding

- Stage 1: Teams work as swift teams. An initial proposal is submitted by a team member, getting to know each other stage

- $\quad$ Stage 2: Group members evaluate each other and indifference, incompetence, imitation and interaction behavior emerge.

- Stage 3: Herding, engagement or dysfunctionality occurs

Next section discusses the Experiment and observations from experiment.

\section{The Experiment and Observations}

The present study was conducted at an urban public university in the Mid-Atlantic area. The university has a non-traditional, commuter diverse student population. We used web MBA and Master of Science accounting students for this study. A database course required of all accounting and MBA/MIS majors was used. Typical student is working full time, has family and takes on line or evening classes. Students were divided in groups of 3 or 4 . Most groups had 3 but some had 4 due to enrollment numbers. Students were give four assignments and the second assignment (a group assignment) was used in this study. First assignment was individual assignment that covered basic structure query language (SQL) and database design concepts. Second assignment was a group assignment that built on the first assignment and consisted of advanced SQL queries and database design concepts. This allowed every participant to have similar basic knowledge in database from first assignment and solution that was available to students. peer's contribution and benchmark was the solution of each case. Each case had peer evaluation and individual grades were adjusted based on peer evaluation. Individual grade was calculated as:

Several groups showed herding which was detected based on group e-mails and group's discussion in the forum area. We selected two groups - one herding (despotism) and one interactive (Democracy) group for this paper.

Our results indicate that teams show herding behavior over time, typically around stage 2 . Teams that share information have equal participation. In addition, we also noted partial herding. This was evidenced by the nature and frequency of communication among team members.

Following section discusses the behavior of two groups. 
Stage 1: Both teams had good start in stage 1. All team members were involved and there was exchange of information. Group members shared accounts and set meetings. There was some attempt for limited communication between members in team members in all teams.

Stage 2: Differences started to emerge in this stage. In one team, a team member posted partial solution and herding started among teams. Communication between members reduced and herding started. This was related to social loafing and lack of functional "competency". In another team group members created sub group and part of the group kept working but one member went loafing.

Stage 3: In one team members accepted solution posted by a team member but group members did not work with the same team in future. Members expressed concerns in surveys and implied distrust among group members. In this group, group members were "indifference" of group outcome and some group members were "incompetent" in functional area to provide any meaningful input. In another team one member "resurfaced" in this stage and started participating, which we call partial herding. This group work resulted in good outcome. Group members did want to work in the same group implying they developed trust over time.

\section{Summary}

In this study, we studied group herding over time. We extended the previous research (Conradt et al, 2009; King et a, 2009; Sun, 2013) on herding by including two additional group member's characteristics, "indifference" and "incompetence". Our study reveals that members start to mimic and herd if they lack domain expertise and/or are indifferent to project to what several researchers (King et al, 2008; Cordant et al..2003) have referred to as despotism.

An interesting finding of our study was that partial herding can occur over time which may self-correct itself or evolve into democracy due to needs and social indifferences (Conradt et al, 2009) or due to presence of uninformed group members (Couzins et al. 2011). In addition, study revealed sub groups are formed if one or more members go in partial or full herding. Sub-groups did not impact group's performance. Our research agrees with (Conradt et al, 2009, King, 2009) that groups whose members are interactive (participatory) and share information over time provide cohesive output and better results However we did not establish any cause-effect relationship at this stage. Our study did show that if there is herding possibilities, managers should address issues after the first stage and not wait for it to resolve by itself as it happened in team 1. Virtual teams are future and team composition is of importance. This raises an interesting question: should managers constantly monitor teams to avoid herding? Our study, though not conclusive, have implications for managers and may provide some guidance on this issue.

\section{Future Research}

There are many interesting research areas related to herding in groups. How herding self-corrects itself in the long run? Can the rewards/punishment related to project motivate group members not to herd? Future research could build upon existing research by replicating it over time across different groups and group sizes. Also, it may be desirable to study group diversity and its impact on herding. In addition, this experiment should be replicated with different group sizes to study the impact of size and diversity on group's herding behavior. Can herding be beneficial as it removes unwilling participants from contribution?

\section{Conclusions}

Herding is way of life for both animals and humans. For animals it is a necessity but for humans it is not desirable since it can create sub optimal outcomes for the group. It is necessary to study factors that cause herding and avoid them. This paper studies herding in small groups and provides guidelines for future research and areas for further study.

\section{References}

Aggarwal, A. (2016, January). Dysfunctional Groups: An Exploratory study. In 2016 49th Hawaii International Conference on System Sciences (HICSS) (pp. 455-462). IEEE.

Aggarwal, A. (2014). Decision making in diverse swift teams: An exploratory study. In System Sciences (HICSS), 2014 47th Hawaii International Conference 
on

(pp.

278-288).

IEEE.

Broeders, D., Chen, D. H., Minderhoud, P., \& Schudel, W. (2016). Pension funds' herding.

Chi S.-P., Chang Y.-Y., Tsou C.-M. (2012). The effect of team characteristics and communication environment to the virtual team performance. International Journal of Networking and Virtual Organisations, 10: 137-152

Conradt, L., \& List, C. (2009). Group decisions in humans and animals: a survey. Philosophical Transactions of the Royal Society of London B: Biological Sciences, 364(1518), 719-742.

Conradt, L., Krause, J., Couzin, I. D., \& Roper, T. J. (2009). "Leading According to Need" in SelfOrganizing Groups. The American Naturalist, 173(3), 304-312.

Conradt L \& Roper T.J. (2003). Group decisionmaking in animals. Nature. 421, 155-158

Conradt, L., \& Roper, T. J. (2005). Consensus decision making in animals. Trends in ecology \& evolution, 20(8), 449-456.

Couzin, I. D., Krause, J., Franks, N. R., \& Levin, S. A. (2005). Effective leadership and decision-making in animal groups on the move. Nature, 433(7025), 513516.

Couzin, Iain D., Christos C. Ioannou, Güven Demirel, Thilo Gross, Colin J. Torney, Andrew Hartnett, Larissa Conradt, Simon A. Levin, and Naomi E. Leonard. "Uninformed individuals promote democratic consensus in animal groups." science 334, no. 6062 (2011): 1578-1580.

Dyer, J. R., Johansson, A., Helbing, D., Couzin, I. D., \& Krause, J. (2009). Leadership, consensus decision making and collective behaviour in humans. Philosophical Transactions of the Royal Society of London B: Biological Sciences, 364(1518), 781-789.

Harrison, D. A. \& Humphrey, S. (2010). Designing for diversity or diversity for design? Tasks, interdependence, and within-unit differences at work. Journal of Organizational Behavior, 31(4), 328-337.
Harrison, D. \& Klein, K. (2007). What's The Difference? Diversity Constructs as Separation, Variety, or Disparity In Organizations, Academy of Management Review, 32(4),1199-1228.

King, Eden., Hebl, Michelle, and Daniel J. Beal, Daniel. (2009). Conflict and Cooperation in Diverse Workgroups, Journal of Social Issues, 65(2), $261-285$

Knippenberg, Van, D., De Dreu, C., Homan, A.C. (2004). Work Group Diversity and Group Performance: an Integrative Model and Research Agenda. Journal of Applied Psychology, 89(6), 10081022.

Knippenberg D.V. \& Schippers, M. (2007). Work Group Diversity. Annual Review of Psychology, Vol. 58, pp 515-541

Kravitz, David. (2005).Diversity in Teams: A TwoEdged Sword Requires Careful Handling, Association of Psychological Science, editorial. Accessed on March 2009. available at: http://www.psychologicalscience.org/observer/getArt icle.cfm?id=1914

Reynolds, A. M. (2013). Effective leadership in animal groups when no individual has pertinent information about resource locations: How interactions between leaders and followers can result in Lévy walk movement patterns. EPL (Europhysics Letters), 102(1), 18001.

Siu Yin Cheung, Yaping Gong, Mo Wang, Le (Betty) Zhou, and Junqi Sh i(2016). When and how does functional diversity influence team innovation? The mediating role of knowledge sharing and the moderation role of affect-based trust in a team, Human Relations.

Sun, H. (2013). A Longitudinal Study of Herd Behavior in the Adoption and Continued Use of Technology. Mis Quarterly, 37(4), 1013-1041. 